\title{
EI Mayo feminista chileno de 2018, en la cresta de la cuarta ola. Uso y apropiación de las redes sociales.
}

\section{The Chilean feminist May of 2018, on the crest of the fourth wave. Use and appropriation of social networks.}

Salomé Sola-Morales*

Carla Quiroz Carvajal**

\section{Resumen:}

Este artículo explora los procesos de apropiación de las redes sociales por parte del Mayo feminista chileno de 2018. Se ha realizado una etnografía virtual y observación participante de las iniciativas digitales llevadas a cabo por parte de las y los actores más relevantes del movimiento: los estudiantes, las organizaciones y las parlamentarias de la Bancada Kirkwood. Se exploró el uso de las principales plataformas online (Facebook y Twitter) y se cuestionó su papel en las protestas en relación con tres ejes: a) identidad de género propuesta, b) lemas y difusión de ideas políticas y c) funciones de las redes sociales. Se concluye que las redes tuvieron un importante rol informativo, como fuentes alternativas al discurso de los medios hegemónicos, expandiendo y visibilizando los temas feministas en la esfera pública y favoreciendo la interacción entre diferentes voces. Predomina una identidad incluyente, que incorpora la unidad en la diferencia, y una multiplicidad de lemas, que evidencia la ampliación del nuevo sujeto político de la cuarta ola feminista: plural y diverso.

Palabras clave: feminismos; Mayo feminista; redes sociales; tecnopolítica; movimiento estudiantil, Chile.

\begin{abstract}
:
This article explores the processes of appropriation of social networks by the Chilean feminist movement in May 2018. There has been a virtual ethnography and participant observation of the digital initiatives carried out by the most relevant actors of the movement: the students, the organizations and parliamentarians of the Kirkwood bench.
\end{abstract}

\footnotetext{
* Doctora en medios, Comunicación y Cultura por la Universidad Autónoma de Barcelona, Magíster en Política y Democracia, Comunicadora, académica de la Facultad de Comunicación, Universidad de Sevilla, España. Con más de 13 años de experiencia investigadora y docente en entre Chile (Universidad de Santiago de Chile) y España (UAB, Universidad Internacional de Cataluña, Universidad de Sevilla, post-doctorado Universidad Complutense) y con más de 50 publicaciones indexadas de impacto internacional, sus líneas de investigación.

** Magíster en Comunicación Social, Periodista, investigadora de la Universidad de Santiago de Chile, Chile. Becaria Chile, Doctoranda en Sociología Universidad de Edimburgo, Escocia.
} 
Revista Punto Género N. 15 Junio de 2021

ISSN 0719-0417 / 201-232

Specifically, the use of the main online platforms (Facebook and Twitter) was explored and their role in the protests was questioned in relation to three axes: a) proposed gender identity, b) slogans and dissemination of political ideas and c) functions of the networks social. The main conclusion reached was that the networks had an important informative role, as alternative sources to the discourse of the hegemonic media, expanding and making feminist issues visible in the public sphere and favoring the interaction between different voices. There is a predominance of an inclusive identity, which incorporates unity in difference, and a multiplicity of slogans, which shows the expansion of the new feminist political subject of the fourth wave: plural and diverse.

Keywords: Feminism; Feminist May; Social Media; Technopolitics; Student Movement, Chile.

Fecha de recepción: Octubre 2020

Fecha de aprobación: Junio 2021

\section{Introducción}

El siglo de las mujeres, como lo llamó Victoria Camps (2013), sigue teñido de violencia a lo largo y ancho del continente latinoamericano ${ }^{1}$. Los números de feminicidios, abuso sexual y acoso contra las mujeres siguen también en aumento en Chile ${ }^{2}$. Para Kathleen Taylor, la directora de la Organización de las Naciones Unidas (ONU) Mujeres para América Latina y el Caribe, el principal refugio de la violencia de género es la impunidad, provocada por la falta de aplicación real de las leyes y por la baja inversión en la infraestructura requerida para la protección real de las víctimas y la sanción de los agresores (ONU, 2017). En Chile, la situación en términos de desigualdad es dramática debido a la brecha salarial, la jubilación, los cuidados de los dependientes, el aborto y la vida pública. Además, el machismo está muy presente en las relaciones familiares y de pareja, la cultura y los medios de comunicación masivos (Cisternas, 2016; Millet, 2010; Oyarzún, 2018; Saavedra \& Toro, 2018).

En el Chile neoliberal, ante la ausencia de un Estado protector y defensor de las mujeres -que garantice sus necesidades y sus derechos, y las posicione en el espacio público de manera justa e igualitaria- y, sobre todo, "ante el cuestionamiento global al modelo de sociedad y de economía neoliberal heredado de la dictadura y mantenido a lo largo de la post-dictadura" (Forstenzer, 2019), la llamada "Primavera feminista" chilena (Ponce, 2018; Ríos Tobar, 2018) o "Mayo feminista chileno" (Zerán, 2018) emerge con fuerza en 2018. Bajo esta última denominación se destaca el momento preciso en que la

\footnotetext{
${ }^{1}$ De los 25 países del mundo con las tasas más altas de feminicidio, 14 están en la región según cifras de la Comisión Económica para América Latina y el Caribe (CEPAL), en: El Economista (20/11/2018) "14 de los 25 países con más feminicidios se ubican en América Latina". Disponible en: https://www.eleconomista.com.mx/politica/14-de-los-25-paises-con-mas-feminicidios-se-ubicanen-America-Latina--20181120-0048.html

2 En Chile, por cada 100 mil mujeres, 0,46 mueren por acción de su pareja. Contreras Gómez, Hugo (2020). "Feminicidios y violencia intrafamiliar contra la mujer". Ciper Académico. Disponible en: https://www.ciperchile.cl/2020/03/07/femicidios-y-violencia-intrafamiliar-contra-la-mujer/
} 
cuarta ola feminista chilena se consolida como la más grande y potente en la historia del país (Seguel, 2018) y es el concepto acuñado en este artículo.

Este estudio exploratorio, descriptivo y analítico revisa los procesos de apropiación de las redes sociales (RRSS) por parte del Mayo feminista chileno, movimiento que surge tras un proceso de rearticulación política en el retorno a la democracia, cuestionando los regímenes de dominación y precarización de las vidas de las mujeres y los cuerpos feminizados y diversos. Mediante la exploración del uso y apropiación de las RRSS por parte del movimiento, se analizan los procesos de construcción de identidades (feminismos plurales, decoloniales y de igualdad en la diferencia); se identifican cuáles son los principales lemas del Mayo feminista; y se describen las funciones de las redes sociales mediante el análisis de las principales estrategias políticas online.

\subsection{Papel de la tecnopolítica en los movimientos sociales latinoamericanos}

En las sociedades globalizadas, donde las relaciones transnacionales son fundamentales y las tecnologías de la información y la comunicación (TIC) una vía clave en la comunicación, los problemas locales van más allá de los límites geográficos de los estados-nación y se convierten en temáticas globales. En muchos países de América Latina y Europa se ha puesto el foco en la lucha feminista y en la batalla contra la violencia hacia las mujeres.

En Chile se están planteando, desde hace décadas, enfoques críticos que denuncian los modos neoliberales en que la tecnología es apropiada por las élites (Joignant, 2011), y la revolución feminista está dentro de este nuevo ciclo de resistencias que han puesto en jaque la forma de hacer política en América Latina (Sierra \& Gravante, 2017, p. 11).Es un feminismo diferente, con un sólido arraigo en lo social, que cuestiona el papel del Estado chileno ausente -propio del modelo neoliberal impuesto durante la dictadura.

La apropiación de la tecnología por parte de los movimientos latinoamericanos en las últimas décadas ha puesto de manifiesto la creciente activación digital (BustamanteFarias, 2014) y el poder de la tecnopolítica y de la cibercultura (Trejo Delarbre, 2012), como matrices que dan opción a "nuevas prácticas, formas de mediación y autoorganización social" (Sierra \& Gravante, 2017, p. 36). Entendemos la apropiación como la forma en que el sujeto político feminista o los feminismos, en este caso concreto, "incorporan la tecnología a sus quehaceres cotidianos, tanto en su dimensión práctica como en su dimensión simbólica (Becerril, 2018, p.75). Las TIC son entendidas como herramientas de comunicación alternativa que vinculan "a las personas y los medios, dentro de un contexto sociocultural, desde los niveles individual, grupal y comunitario" (Sierra \& Gravante, 2017, p. 55), que generan conexiones entre las mujeres, las tecnologías y otros agentes, permitiendo subvertir las relaciones de poder (Pedraza \& Rodríguez, 2019). Estas tecnologías dan voz a los colectivos desfavorecidos y acompañan la lucha y la resistencia contra el poder hegemónico o las políticas dominantes, permitiendo desarrollar formas de expresión y comunicación y favoreciendo 
la organización colectiva (Barassi \& Trere, 2012; Hussain \& Horwars, 2013) de los movimientos.

La perspectiva tecnopolítica pone el foco en la forma de apropiar la tecnología por parte de la ciudadanía como una forma táctica y estratégica de organizar y comunicar la acción colectiva (Toret, 2013). El abordaje feminista de la tecnopolítica, siguiendo la línea de Sonia Reverter-Bañón (2013) o Monserrat Boix (2015), plantea la necesidad de utilizar las TIC para "hackear" e irrumpir en el sistema -que mantiene al patriarcado- y modificar el código a través de la innovación tecnológica feminista.

Los feminismos, desde diferentes lugares del mundo, han comenzado a utilizar y apropiar de forma exponencial Internet y las RRSS y están resignificando las TIC como herramientas que pueden desafiar el orden hegemónico (Laudano, 2017), crear comunidad y potenciar emociones; favorecer prácticas emancipadoras (Wajcman, 2006) y ofrecer alternativas para transgredir los límites del género binario (García-Manso \& Silva e Silva, 2017) así como los patrones hetero-patriarcales y coloniales, de la sexualidad y el deseo (Volkart, 2004) los feminismos latinoamericanos están utilizado las TIC (telefonía digital, correo electrónico, listas de distribución, sitios web y RRSS) de forma relevante como parte de sus estrategias políticas y de movilización (Friedman, 2016).

No todos los movimientos sociales o ciudadanos utilizan las redes sociales y los medios digitales de la misma forma, ni siempre el uso de las TIC se encuentra en el centro de los procesos. En algunos movimientos, la actividad online es esencial para el nacimiento, desarrollo o eclosión social y en otros la actividad virtual acompaña y apoya la actividad offline. Movimientos como el \#Yo Soy 132 mexicano, el \#Metoo (Mendes, Ringrose \& Keller, 2018; Jaffe, 2018), las huelgas feministas y otras formas de "activismo hashtag" (Clark, 2016; Reverter-Bañón \& Medina-Vicent, 2020; Rovira Sancho, 2018; Yang, 2016) han utilizado de forma intensiva las plataformas digitales incorporando innovaciones, otros movimientos, como el estudiantil chileno de 2011, utilizaron las RRSS de manera catalizadora o instrumental, dado que ya existía una estructura de base muy organizada, y solo necesitó que las TIC potenciasen o amplificasen sus actividades (SolaMorales \& Rivera, 2015; Sola-Morales, 2016, 2018).

Tampoco hay que olvidar las relaciones de poder que subyacen en la construcción, diseño e innovación tecnológica. La deriva de los sesgos en los usos algorítmicos (Benítez-Eyzaguirre, 2019) o el impacto del cambio tecnológico sobre los sexos (Wajcman, 2006) son elementos en la base de las relaciones de dominación existentes en los entornos digitales, y que también es preciso subvertir para acabar con la desigualdad y la violencia instalada y reproducida, también online, contra las mujeres, los cuerpos feminizados y diversos.

\section{Orígenes del Mayo feminista chileno}

Las movilizaciones feministas de Chile no fueron un suceso excepcional que estallase el día 17 de abril de 2018 -jornada en la que fue tomada la casa central de la Universidad Austral de Chile, cuando emergió uno de los procesos de movilización social 
más relevantes de la historia reciente del país (Richard, 2018)-. Estas acciones colectivas de protesta se insertaron en un contexto más amplio y complejo: el de la desigualdad estructural que asola Chile (Labra, 2002; Martínez \& Uribe, 2017; Matamala, 2015; Monckeberg Pardo, 2015; Ruiz \& Boccardo, 2015; PNUD, 2017), una de las más agudas del mundo. Esta desigualdad se amplifica cuando se habla de la mujer o de colectivos bajo la etiqueta LGTBI+. En una sociedad patriarcal, el hombre ostenta posiciones de poder en todos los ámbitos de la sociedad (Canales, 2020), que oprimen al mundo femenino (Eltit, 2018) y feminizado, motivo por el cual todas las relaciones sociales se ven mediadas por el patriarcado.

El feminismo chileno tiene una tradición de larga data (Zerán, 2018). La primera etapa u oleada (1913-1949) surgió en un contexto de movilización internacional feminista sufragista (Gaviola Artigas, Jiles Moreno, Lopresti Martínez \& Rojas Mira, 1986). Fue un período de gran desarrollo de organizaciones de mujeres, de diversos sectores sociales, que culminó en 1949, con la promulgación de la ley que autorizó a las mujeres a votar (Gaviola Artigas, Jiles Moreno, Lopresti Martínez \& Rojas Mira, 1986). La segunda ola feminista chilena (1973-1989) estuvo marcada por las movilizaciones contra la dictadura. El movimiento jugó un rol muy importante, vinculando el movimiento de defensa de los derechos humanos, con las demandas propias del feminismo, con consignas como "democracia en el país y en la casa", que ponían de manifiesto la necesidad de luchar tanto en el ámbito público como en el privado (Peñaloza, 2015).

El periodo de posdictadura (1990-2010) se caracterizó por un silencio o desmovilización inicial feminista debido -en parte- al aumento y la pluralidad de actores, sensibilidades e identidades que emergieron (Canales, 2020). Este contexto de fragmentación y falta de unidad dificultó la militancia (Forstenzer, 2012). La creación del Servicio Nacional de la Mujer, SERNAM, en el año 1991, o las iniciativas impulsadas por Michelle Bachelet, primera presidenta del país en 2006, dan cuenta de una institucionalización de las demandas (Forstenzer, 2012). A pesar del importante impacto de las iniciativas al alero del Estado, los feminismos quedaron en cierta medida inhibidos para exigir demandas alternativas desde espacios no-institucionalizados, lo que se debe tener presente al analizar el estallido feminista iniciado en 2018.

Al abordar el momento actual (de 2010 en adelante), Canales (2020) considera que coexisten tres tendencias o corrientes: las vinculadas con la izquierda tradicional; las liberales o libertarias; y las relacionales. Si bien algunas autoras han denominado al período actual en Chile tercera ola feminista (Reyes-Housholder \& Roque, 2019), nos parece que el calificativo cuarta ola (Ponce, 2018, 2020; Zerán, 2018) es más apropiado para categorizar un nuevo período que presenta características propias. En primer lugar, el sujeto político de la lucha feminista se amplía y se consolida como plural (feminismos) y en la diferencia (diversos). En segundo lugar, se proponen una serie de reivindicaciones que van más allá del género y existe una clara repulsa al modelo neoliberal (Ruiz Encina \& Miranda Medina, 2018; Schild \& Follegati Montenegro, 2018). Los feminismos plantean una ruptura antineoliberal (Richard, 2018); antipatriarcal y anticapitalista (Oyarzún, 2018) y buscan acabar con la precarización de la vida que sufren tanto los cuerpos femeninos, como los feminizados y disidentes, y desplazar la matriz androcéntrica que atraviesa 
todas las esferas de la vida en el capitalismo cognitivo, incorporando, además, un marcado tono decolonial (Lugones, 2008). Esta cuarta ola feminista debe leerse en clave decolonial, como apunta Oyarzún (2018). Muestra de ello es la incorporación en su petitorio $^{3}$ del 8 de marzo, alternativas al capitalismo eurocéntrico y global -entendido como hegemónico y colonial, en palabras de Aníbal Quijano (2000) - así como la defensa del pueblo mapuche y la desmilitarización de Wallmapu (Forstenzer, 2019), entre otras cuestiones, generando un feminismo para "la construcción de un orden social alternativo" (Kirkwood, 1987, p. 29). Un orden social, valga reiterar, alternativo al sistema neoliberal y al orden colonial impuesto, implícito en todas las relaciones sociales y en el patriarcado mismo.

En tercer lugar, esta oleada se caracteriza por utilizar un lenguaje directo y confrontador "que recurre incluso al uso de la violencia como medio de "comunicar y sacudir" (Álvarez, 2020. p. 147). En cuarto lugar, esta oleada apropia Internet y las TIC como elemento diferenciador, tal y como ha propuesto Kora Cochrane (2013). En síntesis, Forstenzer la define como una nueva ola, diferente "que nace del Sur global y se expresa mediante la utilización de las redes sociales, lo que facilita su expresión, difusión y recepción, mermando así la posición hegemónica del feminismo occidental blanco" (2019, p. 44) y genera vertientes alternativas al llamado por María Lugones (2008) "sistema de género moderno/colonial", desde la perspectiva de la decolonialidad.

\subsection{Desarrollo de las movilizaciones feministas de 2018 en Chile}

Desde el año 2016 había una acumulación de malestar entre la población a raíz de la brutal agresión sufrida por Nabila Riffo, en Coyhaique, Chile, y organizaciones como Ni una menos o Me too habían llegado a Chile (Muñoz-Saavedra, 2019; Rovira Sancho 2018). El Mayo feminista de 2018 se desató a raíz de varios casos locales de acoso y abuso sexual en el ámbito universitario (Zerán, 2018), violencias que fueron, además, desatendidas y desestimadas por las autoridades universitarias. En el mismo mes de abril, además de producirse la violación de una joven, diferentes actrices famosas denunciaron al conocido director de televisión Herval Abreu, generando una ola de indignación por todo el país ${ }^{4}$, que tomó la violencia contra las mujeres como su principal bandera de lucha. Para Forstenzer esta agitación surgió y constituyó "una culminación y una concretización inesperada de múltiples fenómenos precursores que venían remeciendo la sociedad chilena desde el 2006 y más marcadamente aún, desde el 2010" (2019, p. 45), entre los que cabría destacar la agenda de movilizaciones y petitorios de la revolución pingüina, protagonizada por escolares, y la primavera chilena, por jóvenes

\footnotetext{
3 Véase el petitorio analizado en Paredes, Juan Pablo, Araya, Camila y Ortiz, Nicolás (2019): Primer Informe de Coyuntura de Conflictos Sociales: El mayo feminista 2018. Red Democratización y Movimientos Sociales. Santiago de Chile: Centro de estudios Regionales. Universidad de los Lagos.

${ }^{4}$ Vease: Larrondo, Pia (12/07/2018): "Actrices que denunciaron a herval Abreu entregaron sus testimonios a la fiscalía". Disponible https://www.emol.com/noticias/Nacional/2018/07/12/913041/Las-declaraciones-judiciales-demujeres-que-denunciaron-a-Abreu.html
} 
universitarios, movimientos que habían posicionado en la agenda pública y mediática demandas colectivas en pro de la justicia, los derechos de la ciudadanía y la equidad entre géneros.

Uno de los objetivos fundamentales de las manifestaciones iniciadas en 2018 fue destruir "la estructura ideológica patriarcal de la sociedad chilena con la consiguiente inequidad de género y violencia contra la mujer, expresadas en el acoso sexual en las aulas de nuestras universidades, la educación sexista, el lenguaje discriminatorio y otras lacras" (Zerán, 2018, p.9-10) y, sobre todo, luchar contra la violencia sexual, entendida como un poderoso mecanismo de control social que impide a las mujeres apropiarse del espacio público y hacer uso de su autonomía y libertad (Cobo, 2019), violencia que es permitida y sustentada por el Estado y el sistema neoliberal.

La Universidad Austral fue la primera de las universidades tomada el 17 de abril en repulsa a diferentes casos de acoso y abuso sexual contra estudiantes y profesoras. Le siguieron las universidades de Chile, Andrés Bello y Técnica Federico Santa María. A las tomas se sumaron concentraciones, como la del 3 de mayo en la Universidad de Chile y manifestaciones convocadas por la Coordinadora Nacional de Estudiantes Secundarios (CONES), 9 de mayo; la Coordinadora Ni una menos, 11 de mayo y la CONFECH, 16 de mayo. A fines de junio eran más de 30 las universidades tomadas ${ }^{5}$. El viernes 25 de mayo, la históricamente tradicional y conservadora Pontificia Universidad Católica de Chile fue tomada, por primera vez, por mujeres.

\section{Objetivos de investigación}

El objetivo principal es analizar cómo los principales actores del Mayo feminista chileno apropiaron Internet y las RRSS en el año 2018. Los objetivos específicos son, en primer lugar, explorar las identidades de género propuestas en las RRSS por parte de los principales actores del movimiento; en segundo lugar, describir los lemas e ideas políticas expresadas a través de las RRSS de los principales actores del movimiento, y en tercer lugar, conocer las funciones de las RRSS en el desarrollo del movimiento.

\section{Metodología}

Para explorar los procesos de apropiación de las RRSS por parte del Mayo feminista se ha realizado una etnografía virtual (Hine, 2004, 2005; Laudano, 2018; Mosquera, 2008; Turpo Gebera, 2008) y un análisis y observación participante de las plataformas digitales utilizadas por los principales actores del movimiento. Se ha puesto el foco en los actores en tanto protagonistas de la acción colectiva tras analizar el contexto del Mayo feminista. Las investigadoras participaron como observadoras-usuariasactivistas-feministas dentro del movimiento, asistiendo a manifestaciones, marchas,

\footnotetext{
${ }^{5}$ Para una descripción pormenorizada de las tomas y manifestaciones a lo largo del país véase: De Fina y Figueroa (2019).
} 
asambleas y actos convocados por los diferentes actores en las calles o el espacio público y participando en las RRSS y los espacios virtuales del movimiento.

\subsection{Principales actores del movimiento}

En primer lugar, para delimitar quiénes eran los principales actores del movimiento se ha privilegiado un enfoque multidimensional para ilustrar de forma significativa la heterogeneidad del Mayo feminista como práctica de protesta enmarcada dentro de un entramado social donde hay interacciones y relaciones diversas. Para ello, se delimitaron tres grupos de actores diferentes, con formas de organización, funcionamiento y discursos diferentes: a) el movimiento estudiantil; b) las principales organizaciones ciudadanas feministas y c) las parlamentarias de la Bancada Kirkwood. Con el propósito de dibujar el escenario general y diverso de actores que empujaron y formaron parte del Mayo feminista de 2018, se ha planteado una descripción sucinta -que no pretende ser exhaustiva- de los principales actores seleccionados.

\subsubsection{La CONFECH y las federaciones de estudiantes}

Las movilizaciones feministas de Chile 2018 tuvieron desde su origen una relación muy especial con la institucionalidad y el poder, y concretamente con el movimiento estudiantil (De fina \& Figueroa, 2019; Ponce, 2019) y con los universitarios, en particular (Schuster Ubilla, Santos Pérez, Leibe, Roque López, Arce-Riffo \& Medel Vera, 2019) según algunos investigadores, el Mayo feminista no es más que una prolongación del movimiento estudiantil que ha adoptado una nueva sensibilidad: "feminista y antipatriarcal" (Pedreros Muñoz, 2019, p. 150).

Si bien las convocantes fueron un grupo que pudiera parecer improvisado de estudiantes, movidas por la indignación ante los casos de acoso y abuso sexual contra profesoras y compañeras universitarias, no se puede perder de vista el lugar que ocupan las federaciones de estudiantes y el movimiento estudiantil, en general. La Confederación de Estudiantes Chilenos (CONFECH), federaciones universitarias y otras organizaciones como la Coordinadora Nacional de Estudiantes Secundarios (CONES), tomaron partido ante las protestas, dando todo su apoyo e impulsando las movilizaciones. Esta es la misma dinámica del movimiento estudiantil chileno, impulsado por la CONFECH (SolaMorales, 2016). Ya en 2011 "las federaciones de estudiantes de universidades tradicionales (instituciones de educación superior públicas o privadas que son reconocidas por su trayectoria y su rol social) fueron el instrumento de los estudiantes para posicionar las demandas que salían de las asambleas realizadas en las carreras" (Sola-Morales y Rivera Gallardo, 2015, p. 42). Las federaciones propusieron una forma de energizar el movimiento, como una herramienta de motivación para llevar a cabo múltiples formas de protesta (Sola-Morales, 2018).

La Coordinadora Feminista Universitaria (COFEU) nace en el año 2016 como la Comisión de Género de la CONFECH y busca articular las distintas vocalías de género 
por una educación feminista, la exigencia por los derechos sexuales y reproductivos y el mejoramiento de los estamentos de trabajo.

Aunque más de 32 universidades participaron en las tomas y manifestaciones, las federaciones con más visibilidad en relación con el movimiento feminista fueron la Federación de Estudiantes de la Universidad Austral (FEUACH); la Federación de Estudiantes de la Universidad de Chile (FECH) y la Federación de Estudiantes de la Pontificia Universidad Católica de Chile (FEUC).

\subsubsection{Organizaciones ciudadanas feministas}

Es fundamental reiterar que el Mayo feminista de 2018 tiene un desarrollo y un trabajo de base previo a la fecha de su estallido. Su gestación se dio gracias al apoyo de diversas organizaciones que, ya desde finales de 1990 y con la vuelta a la democracia, iniciaron un proceso de rearticulación política. En este contexto de pos-dictadura surgen en Chile organizaciones muy críticas, entre las que cabe destacar la Red chilena contra la Violencia hacia la Mujer, que hoy también se levanta junto con Ni Una Menos y Coordinadora Feministas en Lucha.

La Red Chilena contra la Violencia hacia las mujeres "es una articulación de colectivos, organizaciones sociales, no gubernamentales y mujeres, que desde 1990, trabaja con el propósito de contribuir a erradicar la violencia hacia las mujeres y las niñas"6. Está conformada hoy en día por 300 diversas organizaciones en todo el país. Entre sus acciones políticas destacan la realización de campañas y su rol como organismo de denuncia, y también investigaciones e intervenciones divulgativas y críticas, generando un catastro de feminicidios, incluyendo aquellos no registrados por la legislación chilena. Con la campaña “¡Cuidado!, ¡el machismo mata!”, la red consiguió posicionarse en la agenda mediática.

Otra agrupación relevante es $\mathrm{Ni}$ una menos Chile. Este colectivo comienza su actividad en Argentina el 3 de junio de $2015^{7}$, haciéndose eco de la lucha feminista contra los feminicidios cometidos en Ciudad Juárez desde la década de los 90'. Bajo el lema “\#Ni una menos. Vivas nos queremos", apoyado y continuado por muchos otros países de la región (Revilla, 2019), el colectivo se moviliza contra las violencias que sufren las mujeres y se consolida como un sujeto político apartidario, plural y heterogéneo.

\subsubsection{Bancada Feminista Julieta Kirkwood}

En enero de 2018 se dio a conocer la conformación de una nueva bancada en el interior de la Cámara de Diputados, cuyo objetivo es defender los derechos de las mujeres. Esta Bancada Julieta Kirkwood (en adelante BK) tomó el nombre de la socióloga y cientista política considerada precursora y fundadora de los movimientos feministas de

\footnotetext{
${ }^{6}$ http://www.nomasviolenciacontramujeres.cl/

7 http://niunamenos.org.ar/quienes-somos/carta-organica/
} 
los años 80' y de los estudios de género en Chile ${ }^{8}$. Las políticas de hoy afirman -como ella- que la batalla ha de darse no solo en el ámbito público, sino también en el privado. "Nosotras hoy venimos a reivindicar que la lucha por los derechos de las mujeres en nuestro país no solo puede darse en el ámbito político sino también en todos los espacios", (Karol Cariola, integrante de la Bancada a El Mostrador, 2018)

La agrupación está conformada por diputadas de distintos partidos: Karol Cariola y Camila Vallejo, del Partido Comunista, Marcela Sabat, de Renovación Nacional y Marcela Hernando, del Partido Radical Social Demócrata; Daniella Cicardini, Maya Fernández, Jenny Álvarez y Denise Pascal, del Partido Socialista, y Cristina Girardi y Loreto Carvajal, del Partido por la Democracia. A pesar de ser nueva y estar menos articulada que las organizaciones ciudadanas y el movimiento estudiantil, nos parece un actor poderoso por su carácter eminentemente político y por ser miembros de ella importantes ex representantes del movimiento estudiantil, como Camilla Vallejo o Karol Cariola.

\subsection{Criterios de selección de los actores}

Dentro de cada grupo, se seleccionó a aquellos organismos o personas que tienen mayor número de seguidores en las RRSS, atendiendo así al criterio de visibilidad mediática:

a) Estudiantes: se seleccionaron las instituciones estudiantiles con mayor visibilidad en los medios, tanto en las principales cabeceras del país, los diarios impresos El Mercurio, La Tercera como en las plataformas online de Facebook y Twitter. Se seleccionaron, por una parte, la COFEU y, por otra, las tres federaciones más relevantes en el movimiento: la FECH, la FEU y la FEAU ${ }^{9}$.

b) Bancada Kirkwood: se eligieron las seis parlamentarias con mayor número de seguidores en RRSS, tratando, además, que fueran de partidos políticos diferentes, para evitar sesgo ideológico.

c) Organizaciones ciudadanas: se privilegiaron las dos organizaciones más importantes en materia feminista en el país: Ni una menos Chile y Red chilena contra la violencia machista.

Tabla 1. Principales actores del mayo feminista chilena 2018

\begin{tabular}{|l|l|l|l|l|l|}
\hline $\begin{array}{l}\text { ORGANISM } \\
\text { O }\end{array}$ & ACTOR & FACEBOOK & $\begin{array}{l}\text { SEGUIDOR } \\
\text { ES }\end{array}$ & TWITTER & $\begin{array}{l}\text { SEGUIDOR } \\
\text { ES }\end{array}$ \\
\hline COFEU & Estudiantes & /cofeu/ & 6.364 & @CofeuMet & 68 \\
\hline FECH & Estudiantes & /fech.uchile/ & 127.905 & @la_Fech & 68.1 mil \\
\hline
\end{tabular}

8 Para profundizar en su figura y en sus aportes véanse: Castillo, A. (2007). Julieta Kirkwood. Políticas del nombre propio. Santiago de Chile: Editorial Palinodia. García, M. (2018). "No hay democracia sin feminismo': Julieta Kirkwood, teoría y docencia feminista para un nuevo contrato social en Chile". Revista Interritórios, 4(6), 93-107.

${ }^{9}$ La relevancia de estas federaciones está explicada en Sola-Morales, S. y Rivera Gallardo, R. (2015). 
Revista Punto Género N. 15 Junio de 2021

ISSN 0719-0417 / 201-232

\begin{tabular}{|c|c|c|c|c|c|}
\hline FEUC & Estudiantes & /FEUC2018/ & 32.982 & @Feuc & $37.8 \mathrm{mil}$ \\
\hline FEAU & Estudiantes & /FEUACh2017/ & 17.738 & @valegaticagg & 457 \\
\hline $\begin{array}{l}\text { BK, Karol } \\
\text { Cariola } \\
\text { (Partido } \\
\text { Comunista) }\end{array}$ & $\begin{array}{l}\text { Parlamentar } \\
\text { ia }\end{array}$ & /karolcariola/ & 36,043 & @KarolCariola & $245 \mathrm{mil}$ \\
\hline $\begin{array}{l}\text { BK, Camila } \\
\text { Vallejo } \\
\text { (Partido } \\
\text { Comunista) }\end{array}$ & $\begin{array}{l}\text { Parlamentar } \\
\text { ia }\end{array}$ & /CamilaVallejoD/ & 172.807 & @camila_vallejo & $1.25 \mathrm{mil}$ \\
\hline $\begin{array}{l}\text { BK, Maya } \\
\text { Fernández } \\
\text { (Partido } \\
\text { Socialista) }\end{array}$ & $\begin{array}{l}\text { Parlamentar } \\
\text { ia }\end{array}$ & /diputadamaya/ & 10.420 & $\begin{array}{l}\text { @Mayafernandez } \\
\text { a }\end{array}$ & $50 \mathrm{mil}$ \\
\hline $\begin{array}{l}\text { BK, Daniella } \\
\text { Cicardini } \\
\text { (Partido } \\
\text { Socialista). }\end{array}$ & $\begin{array}{l}\text { Parlamentar } \\
\text { ia }\end{array}$ & /Daniella.cicardini & 8.521 & @Dani_cicardini & 8.725 \\
\hline $\begin{array}{l}\text { BK, Marcela } \\
\text { Hernando } \\
\text { (Partido } \\
\text { Radical) }\end{array}$ & $\begin{array}{l}\text { Parlamentar } \\
\text { ia }\end{array}$ & $\begin{array}{l}\text { /DiputadaHernan } \\
\text { do/ }\end{array}$ & 13.675 & $\begin{array}{l}\text { @MarcelaHernan } \\
\text { do }\end{array}$ & 6.826 \\
\hline $\begin{array}{l}\text { BK, Marcela } \\
\text { Sabat } \\
\text { (Renovació } \\
\text { n Nacional) }\end{array}$ & $\begin{array}{l}\text { Parlamentar } \\
\text { ia }\end{array}$ & /marcesabat/ & 15.434 & @MarceSabat & $105 \mathrm{mil}$ \\
\hline $\begin{array}{l}\mathrm{Ni} \text { una } \\
\text { menos }\end{array}$ & $\begin{array}{l}\text { Organizació } \\
\text { n ciudadana }\end{array}$ & /niunamenoschile & 12.466 & $\begin{array}{l}\text { @NiUnaMenosC } \\
\text { hile }\end{array}$ & 5.461 \\
\hline $\begin{array}{l}\text { Red chilena } \\
\text { contra la } \\
\text { violencia } \\
\text { machista }\end{array}$ & $\begin{array}{l}\text { Organizació } \\
\text { n ciudadana }\end{array}$ & \begin{tabular}{|l|} 
/Red-Chilena- \\
Contra-la- \\
Violencia-Hacia- \\
las-Mujeres- \\
140943048191/ \\
\end{tabular} & 59.127 & @MujeresRed & $21 \mathrm{mil}$ \\
\hline
\end{tabular}

En segundo lugar, para la realización del análisis de las RRSS se seleccionaron dos plataformas digitales: Facebook y Twitter, por ser las más relevantes en términos de circulación e impacto de las organizaciones seleccionadas. Se descartaron otras plataformas como YouTube o Instagram por resultar su actividad inexistente, testimonial, carecer de relevancia o no aportar diferencias significativas al análisis propuesto. Se han analizado tanto cuentas colectivas como individuales, considerando que estas últimas al tratarse de sujetos públicos/parlamentarias individuales pueden representar el sentir general del ala feminista que cada partido representado incorpora en sus filas.

Para la selección de los ítems que han conformado la muestra se han delimitado seis fechas clave que representan el inicio de las movilizaciones y los eventos más significativos respecto a las movilizaciones y las consecuencias de estas. 
Revista Punto Género N. 15 Junio de 2021

ISSN 0719-0417 / 201-232

Tabla 2. Hitos clave del Mayo feminista chileno

1. Primera toma en la Universidad Austral. 17 de abril de 2018.

2. Toma de la Facultad de Derecho de la Universidad de Chile. 27 de abril de 2018.

3. Concentración en la Universidad de Chile. 3 de mayo de 2018.

4. Manifestación convocada por la plataforma \#Ni una menos. 11 de mayo de 2018.

5. Toma de la casa central de la Pontificia Universidad Católica. 22 de mayo de 2018.

6. Presentación de la Agenda mujer por el presidente Sebastián Piñera. 23 de mayo de 2018.

\subsection{Muestra}

La muestra es acorde a la investigación propuesta -de carácter exploratorio- y no pretende ser representativa, ya que no tiene fines estadísticos. Aporta valor significativo y explicativo que permite ilustrar tendencias y aproximarnos a la comprensión de fenómenos complejos y la "multiformidad" de los movimientos (González, 2019). La han compuesto un total de $\mathrm{N}=253$ publicaciones, 77 de Facebook y 176 de Twitter, que se han recuperado atendiendo a los métodos propios de la etnografía virtual y la observación participante, es decir, de forma manual por parte de las investigadoras-usuariasparticipantes de las RRSS estudiadas. Para delimitar el corpus del análisis se seleccionaron todas las publicaciones realizadas por los tres actores fundamentales del movimiento en las seis fechas clave propuestas.

\subsection{Herramienta de análisis y categorías del estudio}

El análisis de las piezas resultantes $(\mathrm{N}=253)$ ha combinado el análisis de contenido cuantitativo y cualitativo (Piñuel-Raigada, 2002; Krippendorff, 2004), centrándose en la medición de frecuencias de la aparición de las temáticas propuestas. Se ha tratado particularmente de evitar una mirada funcionalista, tecnodeterminista o medio-centrista y se ha propuesto un abordaje situado, otorgando una posición relevante a los actores protagonistas del movimiento como punto de partida y a las investigadoras como sujetos activos que evidencian la relación que se da entre el medio digital y las personas, como sugieren Sierra \& Gravante (2017).

El análisis se realizó en relación con tres ejes temáticos conectados con los tres objetivos específicos del estudio: A) las identidades de género propuestas; B) los lemas o demandas expresados por los principales actores del movimiento y C) las funciones de las RRSS en el desarrollo del movimiento.

\subsubsection{Identidades de género propuestas}

Para profundizar en esta dimensión se delimitaron cuatro categorías: a) identidades incluyentes, b) identidades excluyentes, c) identidades débiles y difusas, así como el marcador d) sin marcadores de identidad. Para el desarrollo de este aspecto se tomó la referencia a "identidades mediáticas" de Víctor Sampedro (2004) y el eje teórico propuesto en Sola-Morales (2013). 
Tabla 3. Identidades de género propuestas en las iniciativas virtuales analizadas

\begin{tabular}{|c|c|c|}
\hline & Definición & Ejemplo \\
\hline $\begin{array}{l}\text { A) } \\
\text { Identidades } \\
\text { incluyentes }\end{array}$ & $\begin{array}{l}\text { - Se hace alusión a las categorías de } \\
\text { pertenencia de forma inclusiva e } \\
\text { integradora. } \\
\text { - Se alejan de la confrontación con otros } \\
\text { colectivos. } \\
\text { - Sus relaciones son pacíficas y } \\
\text { cooperativas. } \\
\text { - Sus valores son la igualdad de } \\
\text { derechos, la universalidad de sus } \\
\text { demandas, la pluralidad. }\end{array}$ & $\begin{array}{l}\text { "Nosotras somos". } \\
\text { "Todas las mujeres". } \\
\text { "Todos los cuerpos } \\
\text { feminizados". } \\
\text { "Todos los cuerpos diversos". } \\
\text { "Todos los feminismos". }\end{array}$ \\
\hline $\begin{array}{l}\text { B) } \\
\text { Identidades } \\
\text { excluyentes }\end{array}$ & $\begin{array}{l}\text { - Relación conflictiva con la otredad. } \\
\text { - Se definen por el valor otorgado a sus } \\
\text { opuestos, negativos y conflictivos. } \\
\text { - Sus valores son la diferencia y la } \\
\text { oposición. }\end{array}$ & $\begin{array}{l}\text { "Nosotras no somos". } \\
\text { "Las mujeres contra los } \\
\text { hombres". } \\
\text { "Mujeres heterosexuales } \\
\text { contra mujeres transexuales". } \\
\text { "Las feministas contra las } \\
\text { mujeres no-feministas". }\end{array}$ \\
\hline $\begin{array}{l}\text { C) } \\
\text { Identidades } \\
\text { débiles }\end{array}$ & $\begin{array}{l}\text { - Sin pertenencia. } \\
\text { - Sin exclusión. } \\
\text { - Ambigüedad, marcadores difusos. }\end{array}$ & \\
\hline $\begin{array}{l}\text { D) Sin } \\
\text { marcadores }\end{array}$ & $\begin{array}{l}\text { La identidad de género no aparece ya que } \\
\text { la temática no se relaciona con las } \\
\text { demandas, necesidades o lemas del } \\
\text { movimiento feminista. }\end{array}$ & \\
\hline
\end{tabular}

\subsubsection{Lemas o demandas expresadas por los principales actores del movimiento}

En una primera etapa se exploraron todos los ítems y su relación con las principales proclamas defendidas por el movimiento feminista. En una segunda etapa, se delimitaron ocho categorías o macro-estructuras, si utilizamos la terminología de Teun A. Van Dijk (1980, 1990, 1991) para englobar los lemas y medir la frecuencia de aparición y, por ende, descubrir cuáles fueron los lemas más defendidos por el movimiento feminista, así como cuestionar si existieron diferencias entre los tres actores clave de las movilizaciones. Las categorías delimitadas fueron las siguientes: 
Tabla 4. Categorías de análisis de lemas del Mayo feminista chileno

1. Fin de la violencia contra las mujeres: proclamas generales contra la violencia estructural y más concretamente contra los feminicidios o asesinatos machistas.

2. Fin del acoso callejero, el abuso sexual y cultura de la violación: demandas que tienen como foco la violencia sexual machista.

3. Pro-aborto: lemas a favor de la legalización del aborto y su despenalización.

4. Igualdad salarial y división sexual del trabajo: propuestas que focalizan en el trabajo.

5. Igualdad en los cuidados y feminización de las tareas domésticas: referencia al reparto de cargas, cuidados y división del tiempo dedicado a las tareas del ámbito privado y familiar.

6. Igualdad en el acceso a la educación: lemas centrados en la igualdad de derechos para estudiar.

7. Educación no sexista: lemas focalizados en la necesidad de fomentar una educación primaria, secundaria y universitaria que no reitere las desigualdades estructurales en la sociedad.

8. Otros lemas: propuestas diversas con menos apariciones o no englobables en las anteriores.

\subsubsection{Funciones de las RRSS en el desarrollo del movimiento}

Aquí se diseñaron categorías instrumentales que describiesen la funcionalidad política de los ítems analizados. Se delimitaron las siguientes estrategias de acción colectiva en la red:

Tabla 5. Función de las redes sociales en la movilización

\begin{tabular}{|l|}
\hline 1. Información sobre convocatorias. \\
\hline 2. Llamada a la participación ciudadana offline. \\
\hline 3. Llamada a la participación ciudadana online. \\
\hline 4. Campaña política. \\
\hline 5. Búsqueda de cooperación. \\
\hline 6. Estrategia de conflicto. \\
\hline 7. Apelación al gobierno. \\
\hline 8. Apelación a la comunidad internacional. \\
\hline 9. Promulgación de ideas o valores, adoctrinamiento político. \\
\hline 10. Publicación de video-creaciones, imágenes no documentales o elementos creativos. \\
\hline 11. Testimonio y cobertura informativa de actividades, manifestaciones. \\
\hline 12. Transparencia, publicación de actas de asambleas, documentos oficiales, petitorios. \\
\hline 13. Votación electrónica. \\
\hline 14. Denuncias, acusaciones o referencia a actos de violencia. \\
\hline 15. Otra función. \\
\hline
\end{tabular}




\section{Resultados}

\subsection{Identidad de género propuesta}

Los resultados del análisis sobre los tipos de identidad aparecidos en los mensajes publicados en Facebook y Twitter analizadas fueron las siguientes. Respecto a la identidad de género propuesta, el relato sobre la inclusión fue el más utilizado en todas las cuentas analizadas. Así, en las cuentas de las organizaciones las narraciones sobre identidades inclusivas sumaron un $51 \%$ del total, en las de los estudiantes un $47 \%$ y las de las parlamentarias un $41 \%$, tal y como se puede ver en la Gráfica 1.

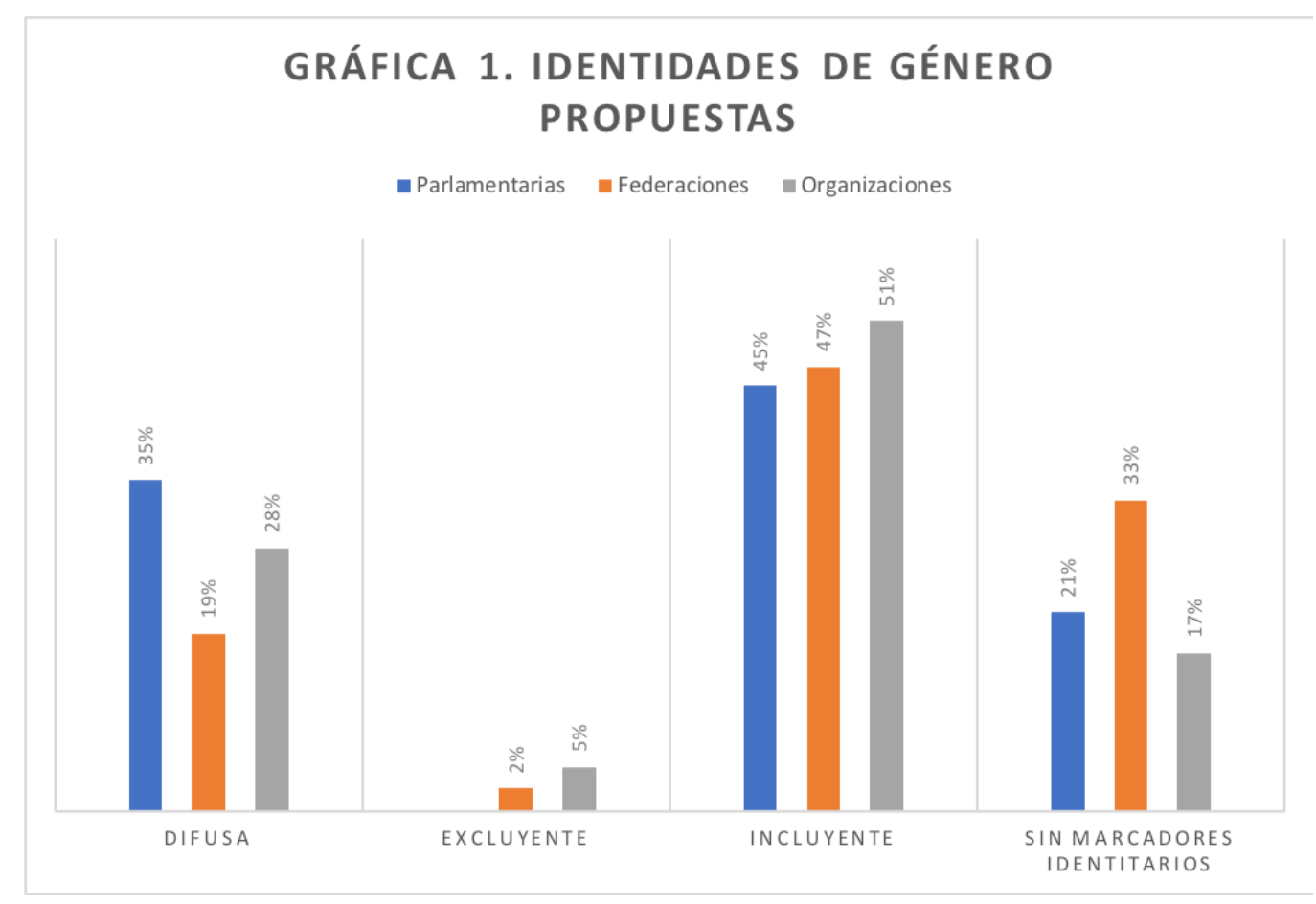

Fuente: Elaboración propia

Si analizamos cada actor por separado se puede observar que las parlamentarias utilizaron sobre todo identidades incluyentes (45\%), identidades difusas (35\%), piezas sin marcadores de identidad (21\%) y en ningún caso propuestas excluyentes. En el caso de los estudiantes, las identidades más utilizadas fueron las incluyentes (47\%), seguidas de ítems sin marcadores (33\%), identidades difusas (19\%) y solo un $2 \%$ de identidades excluyentes. Finalmente, las organizaciones repitieron la lógica, una mayoría de identidades incluyentes $(51 \%)$, seguida de identidades difusas $(28 \%)$, ítems sin marcadores (17\%) y solo un $5 \%$ de identidades excluyentes.

Las identidades propuestas por el movimiento son, por tanto, identidades que pretenden hacer del discurso de las mujeres un discurso universal, de respeto por la diversidad. Si bien en un porcentaje muy escaso de los ítems aparecieron antagonistas los asesinos machistas o los maltratadores-, la mayoría de las piezas analizadas se centraron en identificar el grupo de referencia o caracterizar la comunidad de pertenencia. 
Se hace alusión a las trabajadoras, a las pobladoras, a las estudiantes, a las madres, sin importar clase o condición, tampoco edad o región. Las mujeres son aquí un colectivo incluyente donde todas tienen cabida, así como sus pares los hombres, si las defienden frente a la violencia y las apoyan en la igualdad. Así mismo, se interpela con frecuencia al resto de la sociedad. El colectivo mujeres incorpora a las lesbianas, las migrantes, las trabajadoras, las de la tercera edad, pero también a las pobladoras, las mujeres mapuches, las pertenecientes al colectivo LGTBI+, traspasando los paradigmas binarios y los clásicos constructos de roles. De esta manera, se amplía el grupo de referencia a una categoría común más universal, la de la ciudadana ética y responsable, que respeta y va más allá del rol de género.

\subsection{Principales lemas o demandas expresadas por los principales actores del movimiento}

A través de redes sociales, las federaciones analizadas, las organizaciones feministas y las parlamentarias, en tanto principales actores del movimiento feminista, pudieron instalar en el debate público y en la agenda mediática una serie de temáticas o lemas clave, que constituyen el trasfondo conceptual e ideológico del mismo.

El fin del acoso callejero, el abuso sexual y la cultura de la violación fue el lema preferido por el movimiento feminista tanto en Facebook (29\%) como en Twitter (37\%). Le siguió, en segundo lugar, el marcador "otros lemas", con un $29 \%$ en Facebook y un $20 \%$ en Twitter, lo cual evidencia una cierta dispersión en las demandas, ya que no se apreciaron líneas temáticas comunes dentro de esta categoría.

La proclama a favor de la educación no sexista, con un 17\% en Facebook y un 9\% en Twitter, apareció en tercer lugar. En cuarta instancia estuvieron los mensajes a favor del aborto ( $12 \%$ de los mensajes de Facebook y $10 \%$ de los de Twitter). El fin de la violencia contra las mujeres tuvo mayor cobertura en Twitter (11\%) que en Facebook (4\%). La igualdad salarial obtuvo más presencia en Twitter (8\%) que en Facebook $(5 \%)$ y la igualdad en los cuidados obtuvo porcentajes iguales en ambas redes sociales (5\%), tal y como se puede observar en la Gráfica 2. 


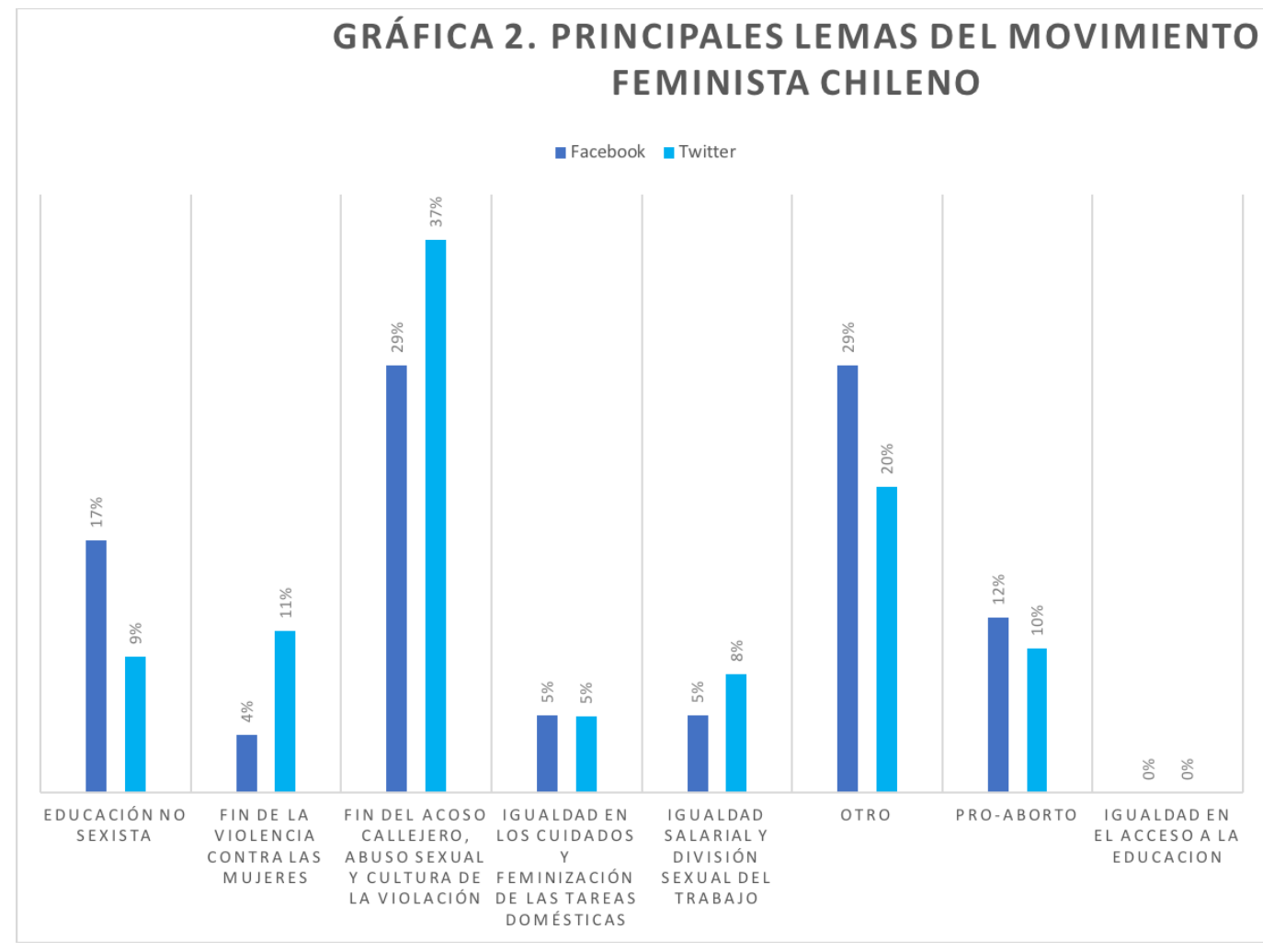

Fuente: Elaboración propia

Para observar si hubo diferencias significativas entre los lemas defendidos, se analizaron los lemas en relación con los tipos de actores de manera independiente (estudiantes, parlamentarias y organizaciones de mujeres). A este respecto se encontraron diferencias entre los actores y la elección del tipo de lema. En el caso de los estudiantes, los lemas preferidos fueron variados (35\%), temas relacionados con el fin del acoso callejero, el abuso sexual y la cultura de la violación (33\%) y educación no-sexista (33\%). En el caso de las organizaciones, el fin del acoso (44\%), el fin de la violencia contra las mujeres $(19 \%)$, otros temas $(17 \%)$ y educación no sexista $(17 \%)$ fueron los lemas preferidos. En lo que respecta a las parlamentarias, las temáticas preferidas fueron variadas $(25 \%)$, fin del acoso callejero, abuso sexual (24\%), temáticas pro-aborto (23\%), igualdad salarial y división sexual del trabajo (13\%) e igualdad en los cuidados y feminización de las tareas domésticas (12\%).

Los estudiantes no trataron ni la temática del aborto, ni las temáticas relacionadas con la igualdad. Además, si bien utilizaron el lema de educación no sexista, no utilizaron la versión de igualdad ante el acceso a la educación. Las federaciones presentaron un discurso muy difuso con una pluralidad de lemas diversos asociados a las diferentes temáticas, siendo el movimiento feminista solo una más dentro de sus demandas.

Al explorar en profundidad las diferencias entre lemas de las parlamentarias pertenecientes a la $\mathrm{BK}$, el único tema defendido por todas las parlamentarias fue el derecho al aborto, como se puede observar en la Gráfica 3. Las diputadas del Partido 
Comunista y de Renovación Nacional fueron las que, en mayor medida, hicieron eco en sus tweets y en publicaciones de Facebook a la necesidad de conseguir la igualdad en los cuidados y reclamaron el fin la feminización de las tareas domésticas. La igualdad salarial también fue otra de las proclamas aparecidas en el discurso de la candidata de Renovación Nacional de manera reiterada. No obstante, la aparición de lemas fue algo testimonial en este grupo. Muchas de las ideas fundamentales asociadas a los hitos que dieron origen a esta ola feminista de 2018, los casos de acoso y abuso sexual, ni siquiera fueron mencionados por las parlamentarias. Es más, en ninguna ocasión las pertenecientes a la BK reclamó el fin de la violencia contra las mujeres o el fin del acoso callejero, el abuso sexual y la cultura de la violación. Las diputadas que sumaron mayor cantidad de lemas fueron Camila Vallejo y Karol Kariola, y Marcela Sabat.

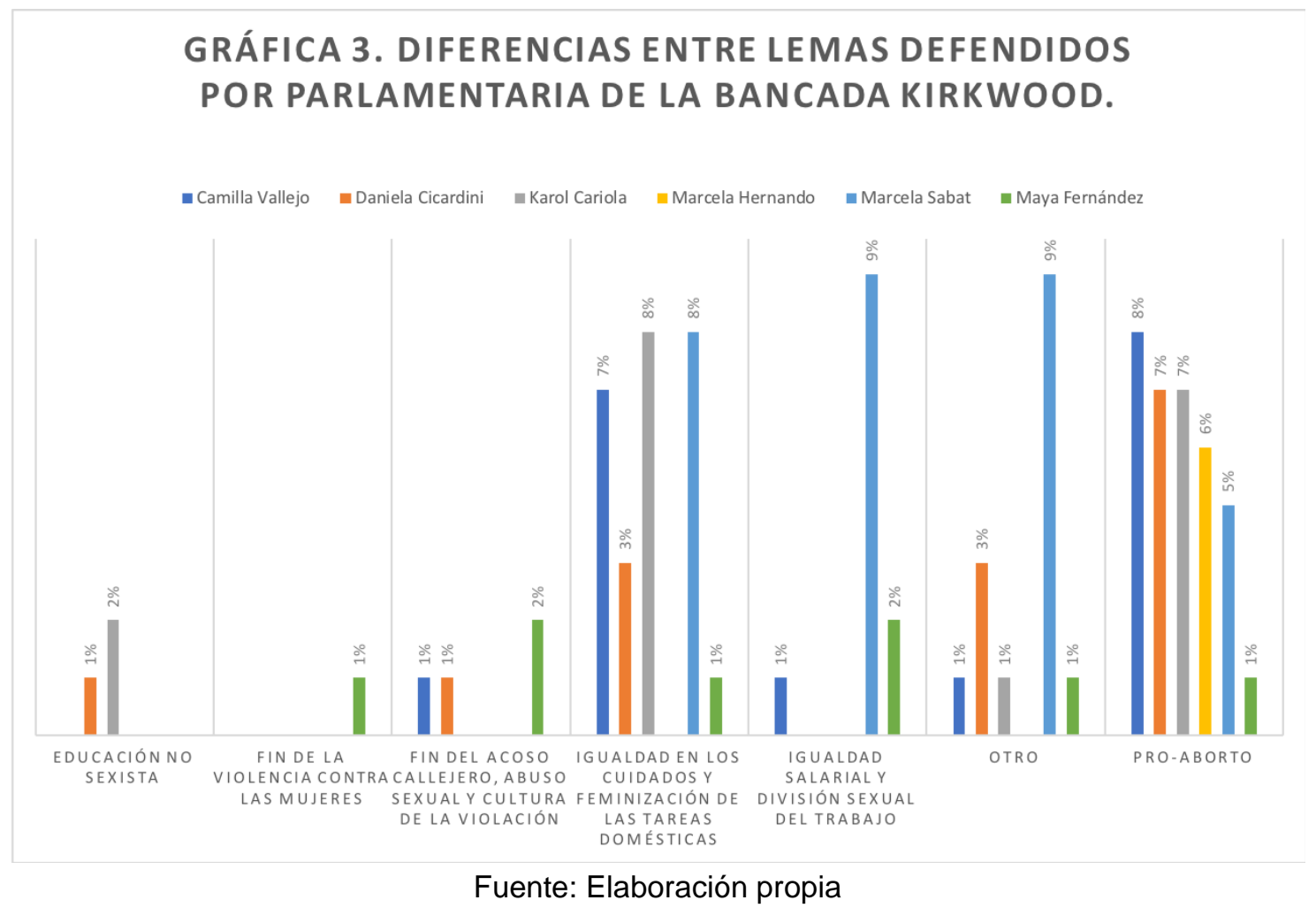

\subsection{Funciones de las redes sociales en el desarrollo del movimiento.}

Un nuevo movimiento social u ola de movilizaciones, que funciona en red, debería estructurarse de forma horizontal y favorecer nuevas vías de participación e interacción virtual. Para explorar cómo se organiza el Mayo feminista chileno en el entorno digital se ha analizado cuáles eran las funciones de las RRSS.

En lo que respecta a las funciones políticas que las RRSS analizadas desarrollaron en el movimiento se pudo observar lo siguiente. La estrategia más utilizada en ambas redes sociales fue dar testimonio y cobertura informativa de actividades y manifestaciones (con $31 \%$ de las funciones en Facebook y un $31 \%$ en Twitter), como se puede observar en la Gráfica 4. 
En segundo lugar, estuvo la estrategia de promulgación de ideas o valores, adoctrinamiento político (con un $19 \%$ en Facebook y un $21 \%$ en Twitter). La tercera de las estrategias más utilizadas fue la publicación de video-creaciones, imágenes no documentales o elementos creativos, que tuvo mayor presencia en Facebook (26\%) que en Twitter (13\%). En cuarto lugar, las piezas analizadas cubrieron la función de transparencia, publicación de actas de asambleas, documentos oficiales, petitorios (Facebook 9\% y Twitter 7\%) y en quinto, las publicaciones se dedicaron a denunciar, acusar o hacer referencia a actos de violencia (12\% en Twitter y $4 \%$ en Facebook). El resto de las funciones tuvieron un rol testimonial, siendo apelación al gobierno $(6 \%$ en Twitter y $4 \%$ en Facebook), la llamada a la participación ciudadana offline (3\% en Facebook, $2 \%$ en Twitter) o la búsqueda de cooperación estrategias (Twitter 3\%, Facebook 2\%) usadas muy poco.

Además, existieron cuatro funciones que no fueron utilizadas en ningún caso: campaña política, estrategia de conflicto, apelación a la comunidad internacional o votación electrónica. Todo ello, lleva a inferir que los mecanismos o estrategias políticas utilizados en las RRSS fueron limitados. En este sentido cubrieron funciones de los clásicos medios de comunicación: tales como informar (función 11, dar testimonio y cobertura informativa), entretener (función 10, publicar video-creaciones o elementos creativos) o, incluso, generar opiniones y divulgar ideas (función 9, promulgar ideas 0 adoctrinamiento político).

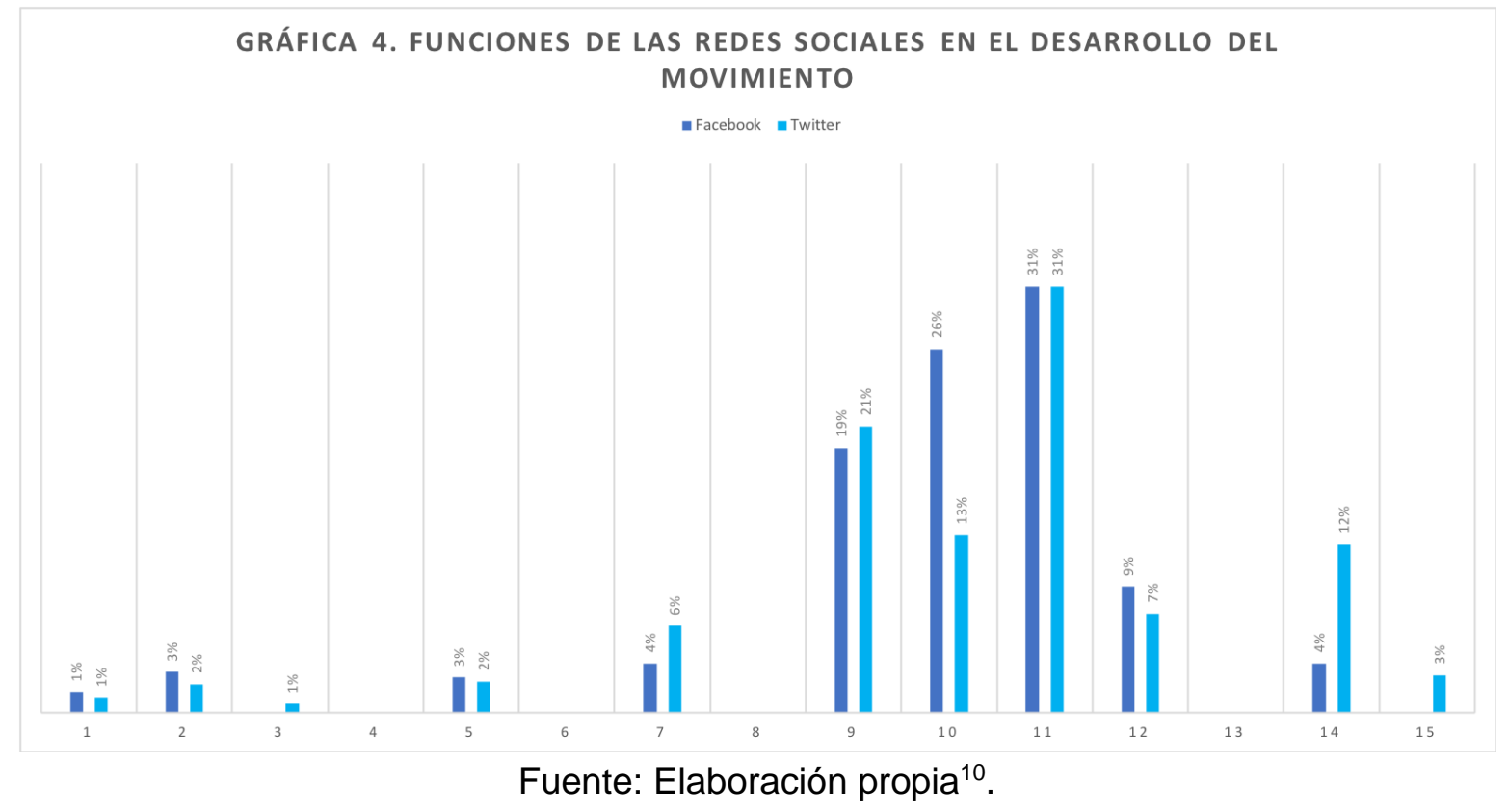

10 Leyenda de las funciones analizadas: 1. Información sobre convocatorias. 2. Llamada a la participación ciudadana offline. 3. Llamada a la participación ciudadana online. 4. Campaña política. 5. Búsqueda de cooperación. 6. Estrategia de conflicto. 7. Apelación al gobierno. 8. Apelación a la comunidad internacional. 9. Promulgación de ideas o valores, adoctrinamiento político. 10. Publicación de video-creaciones, imágenes no documentales o elementos creativos. 11. Testimonio y cobertura informativa de actividades, manifestaciones. 12. Transparencia, 
Revista Punto Género N. 15 Junio de 2021

ISSN 0719-0417 / 201-232

No se hallaron diferencias significativas entre grupos de actores y funciones utilizadas en Facebook y Twitter. Para estudiantes y parlamentarias dar testimonio y cobertura informativa fue la primera estrategia y para las organizaciones la segunda. Lo que evidencia, el rol informativo de las redes sociales analizadas.

En este sentido, las RRSS no fueron utilizadas para debatir propuestas ni para votar decisiones, elementos clave de la deliberación política, simplemente acompañaron como canales de difusión complementarios la actividad política de los voceros de las federaciones, las parlamentarias en el Parlamento y las organizaciones en su quehacer cotidiano. Más que dinamizar el movimiento, las RRSS estudiadas sirvieron como fuentes de información complementaria que dieron cobertura, retro-alimentaron y catalizaron, como la primavera chilena (Sola-Morales \& Rivera, 2015) la actividad offline, dando buena cuenta de que el activismo digital per se no puede reemplazar la movilización social callejera. El uso de las plataformas mediáticas, por parte de los diferentes colectivos analizados bajo el paraguas del Mayo feminista chileno, pone de manifiesto la condición "híbrida" compleja y multifacética del activismo digital, como diría Emiliano Treré (2020), que implica acciones colectivas tanto en las calles como en la red.

\section{Discusión y conclusiones}

A la luz del análisis exploratorio realizado, se puede concluir que el rol de las RRSS en el Mayo chileno 2018 fue fundamentalmente informativo, proporcionando una alternativa al sistema mediático oficial y hegemónico chileno, el cual se encuentra en manos de dos grandes conglomerados de poder, que se reparten el monopolio de la información desde hace décadas en el país. El hecho de favorecer un clima informativo alternativo es crucial en este contexto, dado que expande y visibiliza los temas feministas en la esfera pública, permitiendo la reflexión y sensibilización abriendo un camino para la movilización (Clark, 2016; Linder, Myers, Riggle \& Lacy, 2016). Además, el intercambio de significados y experiencias -que se da en las RRSS- favorece la interacción entre diferentes voces, como ha expresado Guiomar Rovira Sancho (2018). De hecho, el activismo digital, en sus palabras:

"Promueve una nueva dinámica de implicación, con una dimensión de autoreflexividad sobre temas de privilegio, diferencia y acceso. Al juntar diversas formas de feminismos, las plataformas digitales permiten nuevas conversaciones interseccionales que reconocen las opresiones de las personas por su condición de sexo/género en profunda imbricación con la clase, la raza, la colonialidad, la preferencia sexual" (Rovira Sancho, 2018, p. 228).

En relación con la primera pregunta de investigación sobre el uso y apropiación de las RRSS por parte del Mayo feminista chileno de 2018, se puede afirmar que la

publicación de actas de asambleas, documentos oficiales, petitorios. 13. Votación electrónica. 14. Denuncias, acusaciones o referencia a actos de violencia. 15. Otra función. 
actividad y participación virtual desarrollada por los principales actores del movimiento en el período analizado fue escasa, tanto en cantidad (número de publicaciones e iniciativas) como cualidad (diversidad de tipos de iniciativas). A saber, el Mayo feminista no emergió en o desde lo virtual -a raíz de la publicación de un vídeo en YouTube, una convocatoria en Facebook o una recogida de firmas de Change.org, por ejemplo, -como se da el caso en otros movimientos como El yo soy 132 mexicano, la Geraçao à Rasca portuguesa o el movimiento Gilet Jaunes, francés (Sola-Morales, 2020; 2021)-, sino que nació en el espacio offline y en las calles, siendo las acciones virtuales de apoyo (como se puede observar a raíz del análisis pormenorizado y de la observación realizada).

El rol de las RRSS de acompañar la actividad offline es una tendencia muy habitual en los movimientos sociales contemporáneos y no es más que una evidencia de la hibridez de la acción colectiva. El activismo híbrido, tal y como lo entendemos, siguiendo a Emiliano Treré (2020), hace confluir los dos entornos de manera dialéctica y se puede observar tanto en América Latina como en los países del norte global, por ejemplo, con movimientos como 15-M español, que co-implicaron la acción colectiva online y offline de forma simbiótica. En el activismo híbrido la participación virtual puede cumplir la función de catalizar, vehicular o amplificar la acción colectiva convencional, sin ser las TIC o las RRSS un fin en sí mismas. Los repertorios de acción, si utilizamos la terminología de Charles Tilly (2002), no se crean online propiamente, sino offline y son sustentados digitalmente. Este tipo de apropiaciones de las TIC y las RRSS, que podría ser descrito como apoyo y acompañamiento, ha sido catalogado por autoras como Yasmina Welp (2015) como "instrumental" y como no "determinante". El hecho que el uso de las RRSS no sea determinante no significa que la acción online sea menos importante o relevante, sino que no puede ser descrita como el motor esencial de las movilizaciones.

Con respecto a la segunda pregunta de investigación se puede concluir que el uso de las RRSS por parte del movimiento feminista de 2018 no tuvo un componente identitario fuerte. Al contrario de lo esperado, las identidades de género propuestas no fueron de resistencia ni contrahegemónicas en el discurso online analizado. Si bien se podía haber intuido que el discurso feminista de las parlamentarias -por tratarse de la voz institucional- sería integrador y cooperativo, en el caso de los estudiantes y las organizaciones feministas tampoco se mantuvo un tono de resistencia, beligerante en la construcción de identidades o en la contraposición con alteridades diversas. En este sentido, se plantea una identidad de la mujer como colectivo amplio en el que pueden integrarse todas las mujeres -sin distinciones- y en el que todas son bienvenidas: por lo tanto, se encuentra la unidad en la diferencia, en el todas o el todes, algo propio de la cuarta oleada feminista, planteado teóricamente por diferentes autoras. Muchas de las narraciones digitales presentan un componente identitario difuso, lo que resulta especialmente esclarecedor respecto de la ampliación del sujeto feminista que se da en la cuarta ola. En este sentido, la pluralidad de sentires e identidades que componen los feminismos contemporáneos fueron acogidos bajo una unidad en el discurso estudiado: las mujeres, los cuerpos feminizados y diversos, tanto los del cono sur como los del norte comparten emociones recíprocas, como diría James Jasper (2011), de ira, rabia y 
Revista Punto Género N. 15 Junio de 2021

ISSN 0719-0417 / 201-232

hartazgo ante la violencia y la impunidad de los agresores, a través de las RRSS y esto es un importantísimo catalizador de las movilizaciones.

Respecto a la tercera pregunta sobre los lemas expresados a través de los principales actores del movimiento, se puede concluir que las demandas sostenidas en las RRSS son algo ambiguas, en la medida en que no se encontró un discurso mayoritario, homogéneo o bien definido, poniendo de manifiesto -una vez más- el componente plural y diverso del movimiento. Es más, tanto los estudiantes como las parlamentarias se decantaron por la defensa de temas variados entre los que estaban temas de actualidad y de agenda institucional que no tenían relación directa con las tradicionales proclamas feministas -a pesar de tratarse de días clave en los que se produjeron eventos de relevancia informativa en relación con el movimiento. Esto puede evidenciar la transversalidad del movimiento, que emerge como un actor plural que trasciende y amplía sus demandas más allá de la identidad de género, el sexo o la violencia. De los 16 lemas propuestos a priori, más de cinco no fueron recogidos, a pesar de encontrarse expuestos algunos en petitorios estudiantiles, en declaraciones a prensa 0 en asambleas, con lo cual se observa cierta desconexión entre el espacio online y offline.

En relación con la cuarta pregunta de investigación que cuestionaba las funciones de las RRSS en el desarrollo del movimiento, se pudo concluir que la estrategia preferida fue la de testimoniar e informar acerca de las actividades del movimiento y su desarrollo offline. Esta estrategia muestra que los usos de las RRSS analizadas no fueron, por tanto, innovadores en sí mismos. La tecnología funcionó de manera coadyuvante, como elemento complementario a las actividades desarrolladas en la calle, como se pudo observar a la luz de la observación participante y de los contenidos analizados. Los actores analizados también usaron las RRSS para promulgar sus ideas políticas y para publicar video-creaciones, imágenes o montajes creativos, especialmente en el caso de los estudiantes y las organizaciones, que funcionaron para complementar, divulgar y dar apoyo -una vez más a las actividades realizadas en el mundo offline-. En el caso de las parlamentarias, claramente, Facebook y Twitter funcionaron de un modo muy institucional y en cierta medida redundante, ya que las plataformas estudiadas reprodujeron comunicados, ideas y valores ya conocidos o expresados en sus programas o discursos institucionales. En el caso de los estudiantes y las organizaciones quizás se atisbe una funcionalidad un tanto contra-hegemónica, quizás por la condición misma de los actores y organizaciones, y ofrecieron discursos alternativos al de los grandes medios, lo cual es muy relevante en términos de pluralismo y transparencia informativa y complementa las protestas que se dieron en la calle de manera dialéctica.

En definitiva, si bien el Mayo feminista chileno de 2018 forma parte de la nueva corriente feminista latinoamericana, con un marcado tono decolonial y antineoliberal, donde la globalidad y la escala transnacional son esenciales, no se puede afirmar que en este caso particular las RRSS fueran el detonante del o la clave del nacimiento o el arranque del Mayo feminista en 2018.

Vivimos en una sociedad globalizada donde el uso de las RRSS por parte de los actores estudiado se produce en un contexto general de omnipresencia de lo digital, un 
contexto de hipermediaciones, como diría Carlos Scolari (2008), en el que la sociabilidad es mediada por las TIC y, por tanto, las movilizaciones también lo están, en mayor o menor medida. Pero, sobre todo, las usuarias y las activistas protagonistas del Mayo feminista están emplazadas. Primero, en un contexto global de lucha feminista, donde han comenzado a emerger diferentes campañas y movimientos con una importante presencia en las RRSS, como \#NiUnaMenos, \#PrimeiroAssedio, \#EstaEsTuManada, \#AbortoLegalYa, que se expresan a través de diferentes formas de "activismo hashtag", el cual ha sido investigado recientemente (Esquivel Domínguez, 2019; Reverter-Bañón \& Medina-Vicent, 2020) y da buena cuenta de su impacto en términos de opinión pública, solidaridad internacional, alcance transnacional y confluencia, por supuesto, en el espacio virtual entre las violentadas y oprimidas del sur y las del norte. Por tanto, las RRSS permiten crear una comunidad global donde también se da una unión poderosa entre todas y todes las que expresan su malestar contra un sistema, el neoliberal, en el cual la mujer y los cuerpos feminizados y diversos ocupan, siempre, una posición subsidiaria.

En segundo lugar, también hay una situación local particular, una rabia que estalla ante casos locales y ante una acumulación de malestar a nivel país contra el modelo neoliberal chileno, en particular, y contra la opresión del sistema contra las mujeres.

Para terminar, valga apuntar que este estudio exploratorio tiene limitaciones: es acotado y sectorial (solo se analiza un año y se basa en la observación de hitos concretos). Pero es tan solo la primera parte de un trabajo más complejo y profundo sobre feminismos y TIC en Chile. Después de haber realizado esta primera etnografía digital de 2018 se plantea urgente y necesario abrir un espacio a la reflexión y continuar desarrollando una agenda de investigación sobre importantes interrogantes: ¿Acaso el uso tecnológico del Mayo feminista y el posterior estallido feminista es realmente una apropiación planteada desde la tecnopolítica feminista, es decir, desde una perspectiva crítica, feminista y hacker? ¿Puede el uso de plataformas digitales comerciales ofrecer una alternativa al estándar masculino que domina el mundo digital? ¿Es posible a través de RRSS como Facebook y Twitter -empresas paradigmáticas del capitalismo cognitivoluchar contra las desigualdades y los sesgos en los algoritmos? ¿Cuáles son las alternativas feministas a las redes comerciales para subvertir, resistir y emanciparse del sistema hetero-patriarcal, capitalista, colonialista y neoliberal?

\section{Bibliografía}

Álvarez, Lucía (2020): "El movimiento feminista en México en el siglo XXI: juventud, radicalidad y violencia", en Revista Mexicana de Ciencias Políticas y Sociales. UNAM, Vol.65, No 240. p. 147-175.

Arce-Riffo, Javiera \& Medel Vera, Evelyne (2019): "Una mirada al movimiento feminista en Chile del año 2018: hitos, agenda y desafíos”, en IBEROAMERICANA. América Latina-España-Portugal, Vol.19, No. 72, p. 223-245. 
Barassi, Veronica \& Trere, Emiliano (2012): "Does Web 3.0. como after 2.0? Deconstructing theoretical assumptions trough practice", en New Media \& Society, Vo.14, No 8, p. 1269-1285.

Becerril, Walys (2018): "Indagar las apropiaciones tecnológicas desde una perspectiva de género feminista", en Silvia Lago Álvarez, Martín Gendler, Anahí Méndez (Eds.): Acerca de la apropiación de tecnologías: teoría, estudios y debates, p. 65-84. Buenos Aires: Del Gato Gris.

Benítez Eyzaguirre, Lucía (2019): "Ética y transparencia para la detección de sesgos algorítmicos de género" en Estudios sobre el Mensaje Periodístico, Vol. 25, No. 3, p. 1307-1320. https://dx.doi.org/10.5209/esmp.66989.

Boix, Monserrat (2015): "Desde el Ciberfeminismo hacia la Tecnopolítica feminista", en Revista Pillku, No. 18. Recuperado de: https://pillku.org/desde-elciberfeminismo-hacia-la-tecnopolitica-fem/

Bustamante-Farías, Óscar. D. (2014): “Mediatización de la protesta: La activación digital como modalidad de comunicación política. Viaje al centro del movimiento estudiantil 2011 en Chile". Tesis Doctoral. Doctorado en Estudios CientíficosSociales. Tlaquepaque, Jalisco: ITESO.

Canales, Mariana (2020): "Mujer y sociedad. Las corrientes feministas en el debate público chileno", Informe IES. Santiago: leschile.

Camps, Victoria (2013): El siglo de las mujeres. Madrid: Cátedra.

Cisternas, Natalia (2016): Entre la casa y la ciudad. La representación de los espacios públicos y privados en novelas de narradoras latinoamericanas de la primera mitad del siglo XX. Santiago: Editorial Cuarto Propio.

Clark, Rosemary (2016): "Hope in a hashtag. The discursive activism of\# WhylStayed", en Feminist Media Studies, Vol.16, No.5, p. 788-804.

Cobo, Rosa (2019): "La cuarta ola feminista y la violencia sexual”, en Revista Universitaria de Cultura, No. 22, p. 134-139.

Cochrane, Kira (2013): All the rebel women: The rise of the fourth wave of feminism. Londres. Guardian Book.

Contreras Gómez, Hugo (7/03/2020): "Feminicidios y violencia intrafamiliar contra la mujer". Ciper Académico. Disponible en: https://www.ciperchile.cl/2020/03/07/femicidios-y-violencia-intrafamiliar-contrala-mujer/ 
De Fina, Débora \& Figueroa, Francisca (2019): “Nuevos 'campos de acción política' feminista: Una mirada a las recientes movilizaciones en Chile", en Revista Punto Género, No. 11, p. 51-72.

El Economista (20/11/2018) "14 de los 25 países con más feminicidios se ubican en América Latina". En línea: https://www.eleconomista.com.mx/politica/14-delos-25-paises-con-mas-feminicidios-se-ubican-en-America-Latina--20181120$\underline{0048 . h t m l}$

El Mostrador (11/01/2018): "Diputadas crean la nueva Bancada Feminista Julieta Kirkwood". En línea: https://www.elmostrador.cl/braga/2018/01/11/diputadascrean-la-nueva-bancada-feminista-julieta-kirkwood/

Eltit, Diamela (2018): "No hay plazo que no se cumpla”, en Faride Zerán (Ed.): Mayo feminista. La rebelión contra el patriarcado, p. 55-62. Santiago: LOM.

Emol.com (06/06/2018): "Feminismo en Chile: Las organizaciones de mujeres que han impulsado el movimiento". Disponible en: https://www.emol.com/noticias/Nacional/2018/06/06/908785/Recorridohistorico-por-el-feminismo-chileno-Como-se-gesto-el-movimiento-que-hoyvolvera-a-marchar-por-la-Alameda.html

Esquivel Domínguez, Daniela (2019): “Construcción de la protesta feminista en hashtags: aproximaciones desde el análisis de redes sociales”, en Comunicación y Medios, No. 40, p. 184-198.

Forstenzer, Nicole (2012): Politiques de genre et féminisme dans le Chili de la postdictature, 1990-2010, Paris: L'Harmattan.

Forstenzer, Nicole: (2019): Feminismos en el Chile Post-Dictadura: Hegemonías y marginalidades, en Revista Punto Género, No. 11, p. 34-50.

Friedman, Elisabeth Jay (2016): Interpreting the Internet: Feminist and Queer Counterpublics in Latin America. Oakland, CA: University of California.

García-Manso, Almudena \& Silva e Silva, Artenira (2017): "Ciberfeminismo o feminismo en la red: Haciendo arqueología en Internet”, en Antropología Experimental, No 17, p. 277-286. doi: https://doi.org/10.17561/rae.v0i17.3515

Gaviola Artigas, Edda; Jiles Moreno, Ximena; Lopresti Martínez, Lorella \& Rojas Mira, Claudia (1986): Queremos Votar en la Próximas Elecciones. Santiago: ILET. 
González, Gema (2019): "Escraches en redes feministas universitarias: una estrategia contra la violencia de género hacia las mujeres”, en Comunicación y medios, Vol. 28, No. 40, p.170-182.

Hine, Christine. (2004): Etnografía virtual, UOC, Barcelona.

Hine, Christine. (2005): Virtual Methods: Issues in Social Research on the Internet, Berg Publishers, Oxford.

Hussain, Muzammil \& Hooward, Philip. (2013): "What best explain Successful Protest Cascades? ICTs and the Frizzy Causes of the Arab Spring" (Special Issue: International Relationships in the Information Age), en Information Studies Review, Vol.15, No 1, p. 48-66.

Jaffe, Sarah (2018). "The Collective Power of \#MeToo", en Dissent, Vol 65. No. 2, p. 8087. doi: https://doi.org/10.1353/dss.2018.0031

Jasper, James (2011): "Emotions and social movements: Twenty years of theory and research". Annual Review of Sociology, Vol. 37, p. 285-303.

Joignant, Alfredo (2011): “Tecnócratas, technopols y dirigentes de partidos: tipos de agentes y especies de capital en las élites gubernamentales de la Concertación (1990-2010)". en Joignat, Alfredo y Güell, Pedro (Eds.): Notables, tecnócratas y mandarines. Elementos de sociología de las élites en Chile (1990-2010), p. 49-76. Santiago de Chile: Ediciones Universidad Diego Portales.

Kirkwood, Julieta (1987): Feminarios. Santiago de Chile: Ediciones Documentas.

Krippendorff, Klaus (2004): Content analysis: An introduction to its methodology. Thousand Oaks: California: Sage.

Labra, María Eliana (2002): "La reinvención neoliberal de la inequidad en Chile. El caso de la salud", en Cadernos de Saúde Pública, Vol. 18, No.4, p. 1041-1052.

Larrondo, Pia (12/07/2018): "Actrices que denunciaron a herval Abreu entregaron sus testimonios a la fiscalía". Disponible en: https://www.emol.com/noticias/Nacional/2018/07/12/913041/Lasdeclaraciones-judiciales-de-mujeres-que-denunciaron-a-Abreu.html

La Tercera (en prensa): "Alumnas realizan histórica toma en casa central de la Universidad Católica". Disponible en: https://www.latercera.com/nacional/noticia/alumnas-realizan-historica-tomacasa-central-la-universidad-catolica/180645/ 
Laudano, Claudia N. (2018): "Acerca de la apropiación feminista de TICs. EN: Chaher, Sandra, compiladora. Argentina: medios de comunicación y género ¿hemos cumplido con la plataforma de acción de Beijing?" En Memoria Académica. Ciudad Autónoma de Buenos Aires: Comunicación para la Igualdad Ediciones, p. 138-146. Disponible en: http://www.memoria.fahce.unlp.edu.ar/libros/pm.649/pm.649.pdf

Laudano, Claudia N. (2017): "Movilizaciones \#NiUnaMenos y \#VivasNosQueremos en Argentina. Entre el activismo digital y \#elFeminismoLoHizo". Seminário Internacional Fazendo Gênero 11 \& 13th Women's Worlds Congress (Anais Eletrônicos), Florianópolis. Disponible en: http://www.wwc2017.eventos.dype.com.br/resources/anais/1503871106 ARQ UIVO Laudano Texto completo MM FG.pdf

Linder, Chris; Myers, Jess S.; Riggle, Colleen; \& Lacy, Marvette (2016): "From margins to mainstream: Social media as a tool for campus sexual violence activism", en Journal of Diversity in Hig-her Education, Vol. 9, No.3, p. 231-244.

Lugones, María (2008): “Colonialidad y género”, en Tabula Rasa, No 9, p. 73-101.

Martínez, Felipe \& Uribe, Francisca (2017): Distribución de Riqueza no Previsional de los Hogares chilenos. Santiago, Chile: Documentos de Trabajo del Banco Central de Chile Working Papers of the Central Bank of Chile.

Matamala, Daniel (2015): Poderoso caballero. El Pe\$o del dinero en la política chilena. Santiago de Chile: Catalonia, Periodismo UDP.

Mendes, Kaitlynn, Ringrose, Jessica \& Keller, Jessalynn (2018): “\#MeToo and the promise and pitfalls of challenging rape culture through digital feminist activism", en European Journal of Women's Studies, Vol. 25, No.2, p. 236-246. doi: https://doi.org/10.1177/1350506818765318

Millet, Kate (2010): Política sexual. Madrid: Cátedra.

Monckeberg Pardo, María Olivia (2015): El saqueo de los grupos económicos al Estado de Chile. Santiago de Chile: DeBolsillo.

Mosquera, Manuel Andrés (2008): "De la Etnografía antropológica a la Etnografía virtual. Estudio de las relaciones sociales mediadas por Internet", en FERMENTUM. Revista Venezolana de Sociología y Antropología, Vol.18, No 53, p. 532-549.

Muñoz-Saavedra, Judith (2019): "Una nueva ola de feminista... más allá de \#MeToo. Irrupción, legado y desafíos", en Pablo Rivera-Vargas, Judith Muñoz- 
Saavedra, Rommy Morales Olivares y Stefanie Butendieck-Hijerra (Ed.): Políticas Públicas para la Equidad Social, Volumen II., p.177-188. Santiago de Chile: Colección Políticas Públicas, Universidad de Santiago de Chile.

ONU (2017): "Del compromiso a la Acción: Políticas para erradicar la violencia contra las mujeres América Latina y el Caribe”. Documento de análisis regional, Panamá.

Oyarzún, Kemy (2005): "Ideologema de la familia: género, vida privada y trabajo en Chile 2000-2003". En Ximena Valdés y Teresa Valdés (Eds.) Familia y vida privada. ¿Transformaciones, tensiones, resistencias o nuevos sentidos?, 285-293. Santiago: FLACSO Chile.

Oyarzún, Kemy (2018): "Mayo 2018: feminismos en clave descolonial”, en Faride Zerán (Ed.): Mayo Feminista. La rebelión contra el patriarcado, p. 99-113. Santiago de Chile: LOM.

Pedraza, Claudia \& Rodríguez, César (2019): "Conversatorios, talleres y editatonas: tecnopolítica feminista y redes de aprendizaje en México", en Comunicación y Medios, No. 40, p. 84-95.

Pedreros Muñoz, Pedro Maximiliano (2019): "De la consigna "educación gratuita y de calidad" a las tomas feministas. Cartografía singular de mutaciones colectivas de la sensibilidad. Chile, 2011-2018", en La Deleuziana. Revista Online de Filosofía, p. 149-158.

Peñaloza, Carla (2015): "Duelo callejero: mujeres, política y derechos humanos bajo la dictadura chilena (1973-1989)", en Revista Estudos Feministas, Vol 23. No. 3, p. $406-423$.

PNUD (2017). Desiguales. Orígenes, cambios y desafíos de la brecha social en Chile. Santiago de Chile, Programa de las Naciones Unidas para el Desarrollo.

Piñuel-Raigada, José Luis (2002). Epistemología, metodología y técnicas del análisis de contenido, en Sociolinguistic studies, Vol 3, No.1, p. 1-42.

Ponce, Camila (2020): "El movimiento feminista estudiantil chileno de 2018: Continuidades y rupturas entre feminismos y olas globales", en Izquierdas, No 49, p. 1554-1570.

Ponce, Camila (2019): “¿Qué pasa 7 años después del estallido del movimiento estudiantil?: convergencias en los movimientos chilenos de 2018”, en Cátedra, No 16 , p. 171-185. 
Ponce, Camila (2018): "La revolución tiene nombre de mujer", OpenDemocracy, 28 de marzo. Disponible en: https://www.opendemocracy.net/es/la-revoluci-n-tienenombre-de-mujer-el-movimiento-feminista-en-el-cic/

Quijano, Anibal. (2000): “Colonialidad del Poder y Clasi?cion Social”, en Journal of WorldSystems Research, Vol 6, No.2, p. 342-386.

Reyes-Housholder \& Catherine y Roque, Beatriz (2019): “Chile 2018: Desafíos al poder de género desde la calle hasta La Moneda”, en Revista de Ciencia Política, Vol. 39, No.2, p. 191-215.

Reverter-Bañón, Sonia \& Medina-Vicent, María (2020): El feminismo en 35 hashtags. Madrid: Editorial La Catarata.

Reverter-Bañon, Sonia (2013): “Ciberfeminismo: de virtual a político", en Teknokultura. Revista de Cultura Digital y Movimientos Sociales, Vol 10, No 2, p. 451-461.

Revilla Blanco, Marisa (2019): "Del ¡Ni una más! al \#NiUnaMenos: movimientos de mujeres y feminismos en América Latina", en Política y Sociedad. Vol. 56, No 1, p. 47-67.

Richard, Nelly (2018). "La insurgencia feminista de mayo 2018”, en Zerán, Faride (Ed.): Mayo Feminista. La rebelión contra el patriarcado, pp. 115-135. Santiago Chile: LOM.

Ríos Tobar, Marcela (2018) "El año de la primavera feminista" en Revista Capital, Disponible en: https://www.capital.cl/el-ano-de-la-primavera-feminista/

Rovira Sancho, Guiomar (2018): "El devenir feminista de la acción colectiva: las redes digitales y la política de prefiguración de las multitudes conectadas", en Teknokultura. Revista de Cultura Digital y Movimientos Sociales, Vol. 15, No 2 , p. 223-240.

Ruiz, Carlos \& Boccardo, Giorgio (2015): Los chilenos bajo el neoliberalismo: clases y conflicto social. Santiago, Chile: Ediciones y Publicaciones El Buen Aire.

Ruiz Encina, Carlos \& Medina, Camila Miranda (2018): "El neoliberalismo y su promesa incumplida de emancipación: bases del malestar y de la ola feminista”, en Revista Anales, No,14, p. 191-201.

Saavedra, Valentina \& Toro, Javiera (2018): "La revuelta feminista: de la lucha de las mujeres a la lucha por la nueva sociedad”, en Faride Zerán (ed.): Mayo feminista. La rebelión contra el patriarcado, p. 129-142. Santiago: LOM. 
Sampedro, Víctor F. (2004): "Identidades mediáticas e identificaciones mediatizadas. Visibilidad y reconocimiento identitario en los medios de comunicación.", en Revista CIDOB d'Afers Internacionals, No 66-67, p. 135-149.

Seguel A. Natalia, (22/05/2018): "Socióloga, María Emilia Tijoux: 'este movimiento feminista es el más grande de la historia de Chile'”. Disponible en: https://www.radioagricultura.cl/nacional/2018/05/22/sociologa-maria-emiliatijoux-este-movimiento-feminista-es-el-mas-grande-de-la-historia-de-chile.html

Sierra, Francisco \& Gravante, Tomasso (2017): Tecnopolítica en América Latina y el Caribe. Salamanca: Comunicación social.

Schuster Ubilla, Sofía, Santos Pérez, Antonia, Miranda Leibe, Lucía, Roque López, Beatriz, Arce-Riffo, Javiera \& Medel Vera, Evelyn (2019). "Una mirada al movimiento feminista en Chile del año 2018: hitos, agenda y desafíos", en Iberoamericana, Vol. 19, No. 72, p. 223-245. https://doi.org/10.18441/ibam.19.2019.72.223-245

Schild, Verónica \& Follegati Montenegro, Luna (2018): "Contingencia, democracia y neoliberalismo: reflexiones y tensiones a partir del movimiento feminista en la actualidad", en Revista Pléyade, No. 22, p. 157-179.

Scolari, Scolari (2008). Hipermediaciones. Elementos para una teoría de la Comunicación Digital Interactiva. Barcelona: Gedisa.

Sola-Morales, Salomé (2021): "Je suis jaune, Je suis citoyen en colère! Chalecos rmarillos, prácticas tecno-políticas y estrategias ciberactivistas”, en Sierra Caballero, F., Leetoy, \& Gravante, T. (Ed): Democracia inconclusa: Movimientos sociales, esfera pública y redes digitales, p. 241-278. México D.F.: CEICH-UNAM.

Sola-Morales, Salomé (2020): "Precários nos querem, rebeldes nos terão! Tecnopo-lítica e indignación, de la Geração à Rasca a Que se lixe a Troika!", en Anuario Electrónico de Estudios en Comunicación Social. Disertaciones, Vol. 13, No. 2, p. $14-28$

Sola-Morales, Salomé (2018): "The Battle for the Universal and Free Education in Chile: The Use of YouTube in the student Protests of 2011", en Paul R. Carr, Michael Hoechsmann \& Gina Thésée (Eds.): Media, Political Literacy and Education in the Era of Corporate and (Potentially) Participatory Media, p. 161-176. The Netherlands: Sense Publishers. 
Revista Punto Género N. 15 Junio de 2021

ISSN 0719-0417 / 201-232

Sola-Morales, Salomé (2016): "Las redes sociales y los nuevos movimientos estudiantiles latinoamericanos. La «Primavera chilena» y el "YoSoy132»", en IC Journal. Revista Científica de Información y Comunicación, No. 13, pp. 153-193.

Sola-Morales, Salomé \& Rivera Gallardo, Ricardo (2015): "Las redes sociales como catalizador del movimiento estudiantil chileno en el 2011", en Chasqui. Revista Latinoamericana de Comunicación, No. 128, pp. 37-52.

Trejo Delarbre, Raúl (2012): "The Study of the Internet in Latin America: Achievements, Challenges, Future", en Kelly Gates (Ed.): Media Studies Futures. V. 6. The International Encyclopedia of media Studies. Hoboken NJ: Wiley- Blackwell.

Treré, Emiliano (2020): Activismo mediático híbrid. Bogotá: Friedrich-Ebert-Stiftung FES.

Tilly, Charles (2002): "Repertorios de acción contestataria en Gran Bretaña: 1758-1834", en M. Traugott (Comp.): Protesta social. Repertorios y ciclos de la acción colectiva, p. 17- 48 Barcelona: Editorial Hacer

Toret, Javier (2013): (Coord.) Tecnopolítica: la potencia de las multitudes conectadas. EI sistema red $15 \mathrm{M}$, un nuevo paradigma de la política distribuida, en IN3 Working Paper Series, UOC Barcelona.

Turpo Gebera, Osbaldo W. (2008). “Netnografía: Un método de investigación en Internet”, en Revista Iberoamericana de Educación, Vol. 47, No.2, p. 1-10.

Van Dijk, Teun A. (1980): Macrostructures. An Interdisciplinary Study of Global Structures in Discourse, Interaction and Cognition. Hillsdale N.J.: Erlbaum.

Van Dijk, Teun A. (1990): La noticia como discurso: comprensión, estructura y producción de la información. Barcelona: Paidós.

Van Dijk, Teun A. (1991): Estructuras y funciones del discurso: una introducción interdisciplinaria a la lingüística del texto y a los estudios del discurso. México: Siglo XXI.

Volkart, Yvonne. (2004): “La fantasía ciberfeminista sobre el placer del cyborg”, en Lectora Revista Dones Textualitat, No.10, p. 85-111.

Wajcman, Judith (2006): El tecnofeminismo. Madrid: Ediciones Cátedra.

Welp, Yasmina (2015): "Cuando todo lo solido se desvanece en Twitter: Análisis del movimiento \#YoSoy132 (México)", en PostData: Revista de Reflexión y Análisis Político, Vol 20, No 2, p. 417-439. 
Revista Punto Género N.ำ 15 Junio de 2021

ISSN 0719-0417 / 201-232

Yang, Guobin (2016): "Narrative agency in hashtag activism: The case of\# BlackLivesMatter", en Media and Communication, Vol 4, No. 4, p. 13-17.

Zerán, Faride. (2018): "Prólogo". En Zerán, Faride (Ed.): Mayo feminista. La rebelión contra el patriarcado, p. 9-20. Santiago: LOM.

Zibechi, Raúl (2003): "Los movimientos sociales latinoamericanos: tendencias y desafíos, en OSAL: Observatorio Social de América Latina. No. 9, p.185-188 